\title{
$\mathrm{ACT}-\mathrm{R}$ 을 이용한 터치스크린 메뉴 선택 수행 예측
}

\author{
민정상 · 조성식 · 명노해
}

고려대학교산업공학과

\section{Prediction of Menu selection on Touch-screen Using A Cognitive Architecture: ACT-R}

\author{
Jungsang Min, Seongsik Jo, Rohae Myung \\ Department of Industrial Management Engineering, Korea University, Seoul, 136-713
}

\begin{abstract}
Cognitive model, that is cognitive architecture, is the model expressed with computer program to show the process how human solve a certain problem and it is continuously under investigation through various fields of study such as cognitive engineering, computer engineering, and cognitive psychology. In addition, the much extensive applicability of cognitive model usually helps it to be used for quantitative prediction of human Behavior or Natural programming of human performance in many $\mathrm{HCI}$ areas including User Interface Usability, artificial intelligence, natural programming language and also Robot engineering. Meanwhile, when a system designed, an usability test about conceptual design of interface is needed and in this case, analysis evaluation using cognitive model like GOMS or ACT-R is much more effective than empirical evaluation which naturally needs products and subjects. In particular, if we consider the recent trend of very short-end term between a previous technology development and the next new one, it would take time and much efforts to choose subjects and train them in order to conduct usability test which is repeatedly followed in the process of a system development and this finally would bring delays of development of a new system. In this study, we predicted quantitatively the human behavior processes which contains cognitive processes for menu selection in touch screen interface through ACT-R, one of the common method of usability test. Throughout the study, it was shown that the result using cognitive model was equal with the result using existing empirical evaluation. And it is expected that cognitive model has a possibility not only to be used as an effective methodology for evaluation of HCI products or system but also to contribute the activation of HCI cognitive modeling in Korea.
\end{abstract}

Keywords: Cognitive Architecture, ACT-R, Menu-Selection Evaluation

\footnotetext{
1. 서 론

과 조화롭게 연결시킬 수 있는 인터페이스의 개발을 통해 인간-시스템 상호작용을 개선시키면 시스템 사용상의 불편 함을 줄이고 의도하지 않은 실수로 인한 사고를 예방할 수 복잡한 시스템의 작동 방식을 인간의 지각 및 인지 방식 있다. 그러나 제품이나 시스템을 개발하는 경우 단 한 번의

*본 논문은 한국전자통신연구원(10SF1012)과 2010년 정부(교육과학기술부)의 재원으로 한국학술진흥재단의 기초연구사업 지원을 받아 수행된 것임 (Grant No. 2010-0013188).

교신저자: 명노해

주 소: 136-713 서울시 성북구 안암동 5-1, 전화: 010-8915-3392, E-mail: rmyung@korea.ac.kr
} 
인터페이스 설계로 위와 같은 결과를 얻기는 어려우며 '시 제품(Prototype) 설계 $\rightarrow$ 평가 $\rightarrow$ 분석 $\rightarrow$ 재설계'의 과정 을 반복하면서 효율적인 시스템 인터페이스를 얻어낼 수 있 다. 효율적인 시스템 인터페이스란 학습하기 쉽고 오류 발생 이 적으며 숙련되었을 때 적은 노력을 들이고도 빠른 시간 내에 과제 목표를 달성하게 해주는 시스템을 말한다. 이 때 시스템의 인터페이스가 위와 같은 목적에 잘 부합되게 설계 되어 있는지 확인하는 것을 사용성 평가라고 한다. 사용성 평가에는 크게 두 가지 방법이 있는데, 시제품(Prototype) 과 실제 피 실험자를 필요로 하는 실증적 평가(Empirical Evaluation) 과 아키텍쳐를 이용한 분석적 평가(Analytical Evaluation)가 있다.

이러한 사용성 평가를 가장 정확하게 실시하는 방법은 실 제 시스템을 실제 사용자가 사용하게 하여, 배우기 쉽고 오 류가 적으며 수행도가 좋은 지를 평가하는 것이다. 그러나 새로운 기술이나 시스템의 개발 주기가 매우 짧아지는 최근 의 추세를 감안해 볼 때, 시스템 개발단계에서 여러 차례 반 복되어야 하는 사용성 평가를 실시하기 위해 계속 사용자를 선발하고 훈련시키는 것은 시간과 노력이 매우 많이 소요될 뿐만 아니라 자칫하면 시스템 개발이 지연되는 문제점을 유 발시킬 수도 있다. 이와 같이 실제 사용자를 선발하고 훈련 하여 사용성 평가를 실시할 때 생기는 문제점을 보완하기 위한 대안으로 인지 모델링(Cognitive modeling)에 의한 사용성 평가 방법을 들 수 있다.

인지 모델(Cognitive Model) 또는 인지 아키텍쳐 (Cognitive Architecture)는 인간이 어떤 문제를 해결해 나 가는 인지적 과정(Cognitive Process)을 컴퓨터를 이용한 모델로 구현한 것으로, 인간공학, 컴퓨터공학, 인지심리학 등 다양한 학문 분야에서 연구가 이루어지고 있으며, 그 응 용 범위 또한 매우 넓어 사용자 인터페이스 평가, 인공지능, 자연어 프로그래밍, 로봇공학 등 여러 분야에서 주로 인간 의 행동 과정이나 작업 수행을 정량적으로 예측하기 위해 널리 적용되고 있다. 이처럼 인간처럼 생각, 행동할 수 있 는 Cognitive Machine의 생성을 통해 새로운 인터페이스 에서 인간의 과제 수행을 모델링하여 사용성 평가를 실시하 는 것은 실제 실험에 비해 시간, 노력, 비용을 절감시킬 수 있으며, 인간이 실제로 경험하거나 생각할 수 없는 분야에 대한 분석이 가능하다.

위와 같은 인지 모델에는 ACT-R(Anderson, 1983), SOAR (Laird et al., 1987), EPIC(Kieras \& Meyer, 1997) 등과 같이 인간의 행위를 비교적 낮은 수준의 세부행위까지 자세히 묘사할 수 있는 고충실도(High fidelity)의 인지 모 델과 GOMS (Cardet al., 1983) 와 같이 상위 수준의 행위를 묘사할 수 있는 저충실도(Low fidelity) 모델이 국외에서 개발되어 각각의 특성에 부합된 분야에 널리 활용되고 있다.
$\mathrm{ACT}-\mathrm{R}$ 과 같은 고충실도 모델은 인지 과정이나 물리적인 과정 등 인간의 행위를 비교적 자세하게 묘사할 수 있으나 모델링하는 것이 복잡하고 배우기가 어려워 일부 연구자에 의해서만 사용되고 있다. 반면 저충실도 모델인 GOMS는 배우기 쉽고 사용이 간편하기 때문에 인터페이스와 과제의 사용성 평가에 적용하기 편리하여 $\mathrm{HCI}$ 분야 연구에 널리 사 용되고 있다(Olson \& Olson, 1990). 이러한 인지 아키텍 쳐 중 가장 대표적인 모델인 $\mathrm{ACT}-\mathrm{R}$ (Adaptive Control of Thought - Rational)은 지금까지 개발된 여러 가지 인지 아키텍쳐 중에서도 인간의 인지 과정을 vision, cognition, audition, psychomotor 등 하위 수준까지 가장 세부적으로 그리고 정량적으로 정확히 묘사할 수 있는 것으로 인정받고 있다(John \& Kieras, 1996). 또한 그 뿐 만 아니라 ACT-R 은 사용자의 레벨(Level)을 임의로 조작할 수 있으며 병렬 적인 과정을 나타낼 수 있으며, 학습 효과나 에러 등도 예 측하거나 나타낼 수 있다(Anderson, 1996). 고충실도 모 델인 SOAR나 EPIC의 경우 위와 같은 일련의 과정을 표현 할 수 있지만 그 과정이 실제 인간과는 다소 차이가 있는 등의 이유로 $\mathrm{ACT}-\mathrm{R}$ 에 대한 연구가 가장 활발히 진행되고 있는 실정이다(Anderson et al., 2004).

ACT-R은 1973년에 발표된 HAM(Human Associative Memory)이론 (Anderson \& Bower, 1973)을 기원으로 1983년 ACT라는 이름으로 시작되었고, 20여 년 간에 걸 쳐 많은 학자들에 의해 연구된 여러 이론과 실험의 결과가 계속 반영되면서 6.0버전까지 발전되어 현재 ACT-R 6.0 은 인간의 과제 수행시간과 정확도, 두뇌 활동에 대한 정보 등을 산출할 수 있는 능력을 가지게 되었다(Taatgen et al., 2004).

앞에서 간단하게 언급되었듯이 초기에는 인지심리학 분야 인 학습과 기억, 문제 해결과 의사 결정, 언어와 의사 소통, 지각과 주의, 인지 발달, 개인 간 차이 등의 영역에 주로 적 용되었다. 그러다가 1998년 Perceptual module과 Motor module이 추가된 ACT-R/PM이 개발되었고(Byrne \& Anderson, 1997) 2001년 이를 Menu Selection에 적용한 "ACT-R/PM and menu selection: applying a cognitive architecture to HCI" (Byrne, 2001)라는 논문이 발표되면 서 본격적으로 $\mathrm{ACT}-\mathrm{R}$ 이 $\mathrm{HCI}$ 분야에서 사용자 모델을 수 립하기 위한 도구로 이용되기 시작하였다.

현재까지 인지 아키텍쳐인 ACT-R을 통한 메뉴 선택에 대한 연구는 수 차례 진행되어 왔다. 대표적인 인지 아키 텍쳐인 GOMS, ACT-R과 수학적 모델인 Fitts' Law를 이용하여 핸드폰 메뉴를 선택하는 연구(Amant \& Horton, 2007)가 있었다. 하지만 이는 한번에 3가지의 메뉴만 보여 주는 제한된 디스플레이에서 진행되는 인간의 수행도를 예 측하는 연구였고, Hick-Hyman Law, Fitts' Law를 이용하 
여 Laptop 컴퓨터에서의 메뉴 선택 과정을 예측한 연구 (Cockburn et al., 2007)는 그 환경이 컴퓨터상에 국한된 것뿐만 아니라 인지 아키텍쳐를 이용한 것이 아닌 수학적 모델을 기반으로 수행도를 예측한 연구이다. 또한 간단한 숫자를 보고 하위 메뉴에서 선택하는 연구(Nilsen, 1991) 역시 실제로 사용되는 실용적인 메뉴 구조가 아닌 보여지는 숫자를 하위 메뉴에서 찾는 실험적인 연구일 뿐이었다. 이 를 포함한 여러 인지 아키텍쳐를 이용한 연구들이 국외에서 는 지속적으로 진행되어 왔다.

하지만 본 연구는 이들의 연구와는 차별적으로 현재 가장 많이 사용되는 Input device 중에 하나인 터치스크린 환경 으로 연구를 진행하였으며 그 메뉴 구조 역시 상용화되고 있는 핸드폰의 메뉴 구조를 구현하여 실시하였다. 또한 메 뉴 선택에 대한 수행도를 예측하기 위한 인지 아키텍쳐는 현재까지 가장 많이 연구되고 있는 $\mathrm{ACT}-\mathrm{R} 6.0$ 버전을 이 용하여 메뉴 선택 예측 모델을 제안하였다. 즉, 기존까지 사 용되던 정적인 메뉴 구조와 터치스크린 환경을 고려한 동적 메뉴 구조를 $\mathrm{ACT}-\mathrm{R}$ 로 수행 예측을 한 뒤, 실제 실험 데이 터와 비교하였고, 이는 모델을 기반으로 한 사용자 메뉴 선 택 예측을 목적으로 하고 있다.

\section{2. 연구 방법}

본 연구에서는 1 열 메뉴 구조를 정적 메뉴 구조와 동적 메뉴 구조로 나누어 각각에 대해 수행도를 예측하는 모델을 수립하였고, 이를 기존의 연구 결과(Kong et al., 2009)인 실제 피 실험자의 Data와 비교, 분석하였다. Kong (Kong et al., 2009) 연구는 6 개의 과제를 통하여 정적, 동적 메뉴 중 어느 메뉴 구조가 더 좋은 수행도를 보여주느냐를 연구한 것으로, 그 결과 동적 메뉴 구조가 정적 메뉴 구조보다 더 나은 수행도를 보이는 것으로 나타났다.

\section{1 실험 장비}

실험 장비는 International Allegro Common Lisp Professional Edition 8.2 프로그램을 시용하였고 ACT-R 6.0 인지 아키텍쳐로 모델을 수립하였다. ACT-R의 모델을 수립하기 위하여 먼저 실제 실험과 동일한 Task 환경을 구 현하였다. ACT-R의 기본 언어인 LISP을 이용하여 Kong (Kong et al., 2009)에서 MFD Tool로 구현한 메뉴 구조의 모양과 크기 등 실험 환경에 대한 조건을 동일하게 만들었다.

Figure 1은 본 실험에 사용된 정적 메뉴 구조의 메인 메 뉴와 하위 메뉴를 보여준다. 각 메뉴의 크기는 너비 $40 \mathrm{~mm}$,
높이 $124 \mathrm{~mm}$ 이며 총 12 개의 버튼으로 구성되어 있다. 그 러므로 각 버튼의 크기는 너비 $40 \mathrm{~mm}$, 높이 $8.5 \mathrm{~mm}$ 이며 버튼과의 간격은 $2 \mathrm{~mm}$ 이다. 최초의 메인 화면의 메뉴 구조 는 총 12 개의 버튼으로 구성되어 있고, 이 중 9 개의 메뉴 item이 최상단으로부터 배치되어 있다. 배치되지 않은 나머 지 3 개의 메뉴 item은 최하단에 빈 칸으로 배치되어 있다.

일반적으로 정적인 구조에서는 앞서 말한 바와 같이 상위 메인 메뉴에서 메시지라는 메뉴를 선택하였을 때 하위 메뉴 구조의 최상단에서부터 메시지와 관련된 하위 메뉴 item의 배치가 시작된다. 상위 메뉴에서 선택된 메뉴와 관련된 하위 메뉴는 각 시나리오 별로 4 8개로 각 상위 메뉴 item마다 상이하다.

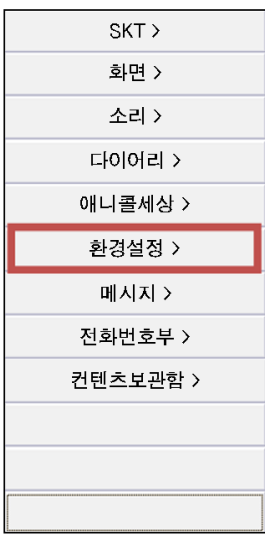

(a) 메인 메뉴

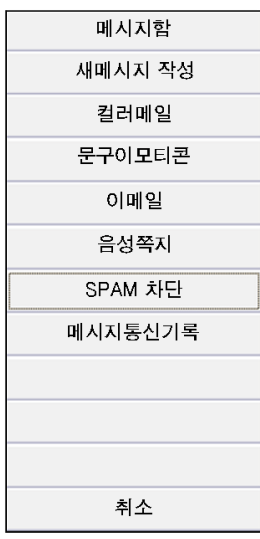

(b) 정적 하위 메뉴
Figure 1. 정적 메뉴 구조

이에 반해, 동적 메뉴 모델은 터치스크린에서의 한 손가 락 작업 환경의 물리적 특성 및 이에 따른 사용자들의 단순 한 인지 과정을 고려한 구조(Kong et al., 2009)이다. 이는 물리적인 손의 움직임과 인지적 시선의 움직임을 최소화하 기 위해 하위 메뉴를 상위 메뉴의 마지막 선택 지점에 가깝 게 배치한 것으로 Figure 2와 같다. 동적인 구조에서는 메 시지라는 상위 메뉴를 선택하였을 때 가장 많이 사용하는 메시지 함이라는 하위 메뉴가 상위 메뉴의 위치에 나타나고 그 주위로 다른 하위 메뉴들이 빈도수에 따라 순서대로 배 치되게 된다. 즉, 선택을 했던 자리 근처에서 가장 자주 사 용하는 메뉴들이 나타나게 되는 것이다((Kong et al., 2009) (Figure 2)).

하위 메뉴에서 메뉴 item이 배치되는 순서는 Figure 2 와 마찬가지로 상위 메뉴에서 선택했던 위치에 가장 높은 빈도 수인 메뉴가 나타나고, 그 아래가 2 번째로 많이 사용되는 메 뉴 item이 배치되고, 그 위는 3번째로 사용되는 메뉴 item 이 배치되게 하였다. Figure 2(b) 하위 메뉴 구조의 각 item 


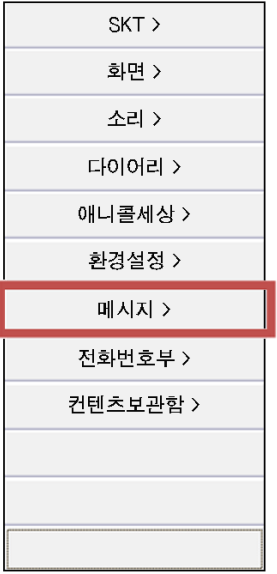

(a) 메인 메뉴

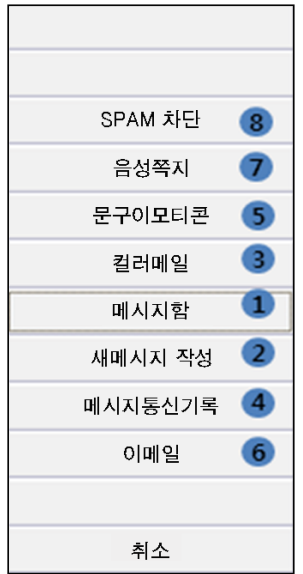

(b) 동적 하위 메뉴
Figure 2. 동적 메뉴 구조

에 포함된 숫자는 빈도수의 순위를 의미하며 다른 하위 메 뉴도 위와 동일한 방법으로 배치하였고 나머지 부분은 공란 으로 배치하였다. 그리고 가장 마지막 메뉴 item은 '취소'로 배치하여 실험을 진행하였다.

\section{2 모델 수립을 위한 가정}

본 연구의 $\mathrm{ACT}-\mathrm{R}$ 모델에서는 visual 전략을 메뉴 하나 하나를 눈으로 확인하고 attention을 옮기는 Exhaustive attention을 사용한 기존의 모델(Nilsen, 1991)과는 다르 게 메뉴를 2 개씩 보도록 정의 하였다. 이는 인간의 중심와 (fovea)의 각도가 $2^{\circ}$ 이며 모니터와 피 실험자의 거리가 $500 \mathrm{~mm}$ 임을 근거로 계산하였을 때 한 눈에 볼 수 있는 길 이가 $175 \mathrm{~mm}$ 임을 이용한 것이다. 이 길이는 구현된 메뉴 구조의 버튼 크기를 고려할 때 2 개의 메뉴를 볼 수 있는 공 간이므로 본 연구에서는 메뉴를 2개씩 보고 visual attention 을 옮기도록 하였다.

\section{3 모델 수립}

본 연구의 Menu Selection 모델을 구성하고 있는 Production Rule은 크게 4가지로 구성되어 있다. 타겟을 찾는 과정, Attention을 옮기는 과정, 그리고 찾고자 하는 타 겟이 현재 보고 있는 버튼과 같은지 혹은 다른지를 확인하고 마우스를 움직여 선택을 하거나 혹은 다시 타겟을 찾는 과 정이다. 이들 Production Rule의 순서도는 다음의 Figure 3 와 같다.

Figure 3에서 보여지는 'Find-button-location 1 6'은 타겟 메뉴를 찾는 Production Rule로써, 하위 메뉴가 총

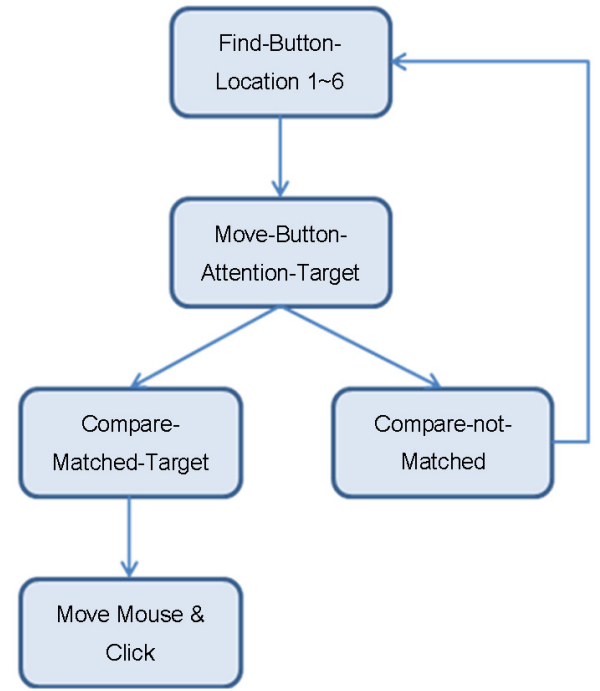

Figure 3. Production rule의 순서도

12 개의 메뉴 구조로 이루어져 있으므로 6 개의 구역으로 나 누어 보는 것으로 수립하였다. 모델이 보는 각 구역은 정적 메뉴와 동적 메뉴 따라 달라지게 만들었는데 이는 정적이 냐 동적이냐에 따라 그 시각적 탐색의 전략이 각각 다르 기 때문이다. 정적인 모델의 경우 하위 메뉴의 item이 최 상단에서부터 배치되기 때문에 시각적 탐색을 최상단에서 부터 실시하도록 모델을 수립하였고, 동적인 모델의 경우 메인 메뉴에서 선택한 위치에서부터 메뉴 item이 배치되기 때문에 해당 위치에서부터 시각적 탐색을 하도록 모델을 수 립하였다. 'Move-button-attention-target'은 현재 보고 있는 곳으로 Attention을 옮기도록 하는 Production Rule 로써 본 모델의 시각적 전략의 가정에 따라 2개 메뉴씩 Attention을 옮기도록 하였다. 'Compare-matched-target' 와 'Compare-notmatched'는 찾고자 하는 타겟과 현재 모델이 보고 있는 버튼이 맞는지 혹은 아닌지를 확인하는 Production Rule이다. 가령, 찾고자 하는 타겟과 보고 있는 타겟이 맞으면 'Move Mouse \& Click'을 이용하여 마우스 를 움직여 클릭을 수행하고, 그렇지 않은 경우에는 다시 타 겟을 찾는 'Find-button-location 1 6' Production Rule 을 수행하도록 모델을 수립하였다.

\section{4 과제 수행 절차}

본 연구에서 진행되는 과제에 대한 절차는 다음과 같다.

본 모델의 Goal은 특정 타겟 메뉴를 선택하는 것이며, Lisp을 통해 만들어진 윈도우 창의 "GO"라는 버튼을 누르 고 최종 타겟을 보는 것으로써 시작이 된다. 이를 클릭하게 되면 첫 번째 메인 메뉴 화면이 나타나고 최종 타겟과 연관 
이 있는 메뉴를 찾아 선택한다. 가령 타겟 메뉴가 "메세지" 라 할 경우 그 상위 메뉴에서 "메시지 함"을 선택해야 한다. 이와 관련하여 모델의 Declarative Memory에 타겟과 연관 된 정보를 Chunk 형태로 미리 저장해 두었다. 마지막으로 모델은 타겟 메뉴 item를 찾아 누르는 행위를 하게 된다. 실 제로 피 실험자와의 데이터를 비교하기 위해 마지막 단계의 시간을 따로 산출하여 비교하였다.

\section{3. 연구 결과}

\section{1 정적 메뉴 모델}

본 연구 결과 실제 피 실험자를 중심으로 한 실험 데이터 (여기서의 실험 값은 Kong(2009)의 실험 값이다.)와 인 지 모델의 예측 값을 $\mathrm{t}$-test로 분석한 결과 6 개의 task 중 모두 통계적으로 평균의 차이가 다르지 않다는 것을 알 수 있었다(Table 1).

Table 1. 정적 모델의 결과 비교(ms)

\begin{tabular}{c|c|c|c|c}
\hline Task & 모델 & 실험평균 & 표준편차 & $p$-value \\
\hline Mplayon & 1118 & 1101 & 109 & 0.32 \\
\hline 메세지함 & 1137 & 1146 & 105 & 0.24 \\
\hline 카메라 보관함 & 1095 & 1150 & 67 & 0.22 \\
\hline 연락처 검색 & 1137 & 1275 & 106 & 0.43 \\
\hline 연락처 등록 & 1262 & 1390 & 125 & 0.22 \\
\hline 새메세지 & 1113 & 1312 & 57 & 0.20 \\
\hline
\end{tabular}

특히, 정적 메뉴 모델은 피 실험자들의 행위 패턴을 그대 로 따르고 있음을 확인할 수 있었다(Figure 4). 또한 모델 의 예측 값과 실제 값의 상관관계 분석을 하기 위하여 회귀

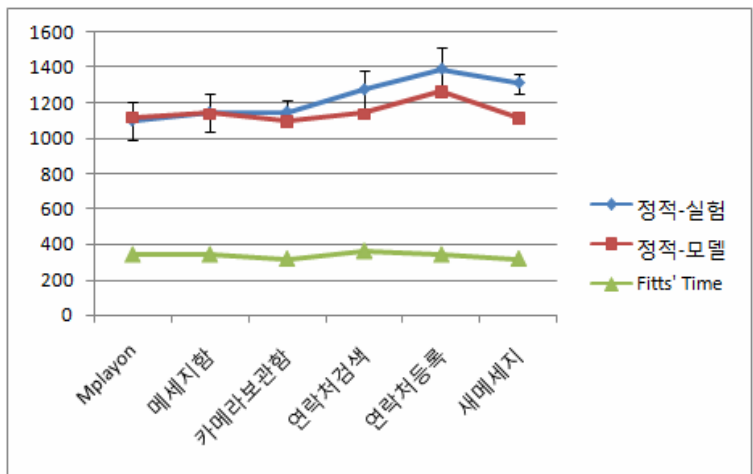

Figure 4. 정적 모델의 결과 그래프
분석을 실시한 결과 다중 상관계수인 $\mathrm{R}^{2}$ 값이 0.92 로 높은 상관관계가 있음을 알 수 있었다. 그리고 모델의 예측 값을 통해 실제 값을 도출할 수 있는 결정력을 의미하는 결정 계 수는 0.84 로 분석되었다. 따라서 정적 메뉴에 대한 수행 예 측 모델이 정확하게 수립되었음을 확인하였다.

뿐만 아니라 결과 분석을 통해 전체 수행시간 중 물리적 인 시간만을 도출할 수 있어 추가적인 정보를 확인할 수 있 었다. 즉, 정적인 모델은 전체 수행시간 중 물리적인 시간이 차지하는 비율은 25\% 정도였고(317 361ms) 나머지 시 간은 인지적인 시간으로 확인되었다. 주어진 6 가지의 과제 에 따라 전체 수행시간은 차이가 나는 반면 물리적인 시간 의 차이는 나지 않는 것으로 분석되었다. 이는 Kong(2009) 의 연구 결과와 마찬가지로 물리적인 이동거리는 전체 수행 시간에 큰 영향을 미치지 않는다는 것으로 확인할 수 있었 으며 그 이외의 시간인 인지적 과정이 전체 수행도에 큰 영향을 미치는 것으로 분석되었다.

정적인 모델의 경우 Mplayon에서부터 연락처 등록으로 갈수록 그 수행시간이 오래 걸리는 것으로 나타났는데 이 는 과제의 난이도가 어렵다기 보다는 메뉴 item마다 배치 되어 있는 위치가 다르므로 그로 인한 인지적인 과정의 차 이로 볼 수 있다. Nilsen(Nilsen, 1991)의 연구 결과에서도 이와 같은 결과를 확인할 수 있었다.

\section{2 동적 메뉴 모델}

동적 메뉴 모델 역시 실험 값과 모델의 t-test 결과 두 평균의 차이가 다르지 않음을 확인하였다(Table 2). 이는 정적인 모델과 마찬가지로 모델의 예측 값이 실제 값을 정 확히 예측한다는 것을 의미하며, 이 둘간의 상관관계와 결 정 계수 등을 확인하기 위해 회귀분석을 실시하였다. 동적 메뉴 모델의 경우 예측 값과 실제 값과의 상관계수 $\mathrm{R}^{2}$ 값이 0.98로 매우 높게 확인되었고, 결정 계수는 0.96으로 분석 되었다. 이는 모델의 예측 값만을 통해서 실제 실험 값을 충 분히 예측할 수 있음을 의미한다.

Table 2. 동적 모델의 결과 비교(ms)

\begin{tabular}{c|c|c|c|c}
\hline Task & 모델 & 실험평균 & 표준편차 & $p$-value \\
\hline 메세지함 & 653 & 681 & 103 & 0.31 \\
\hline 연락처 검색 & 641 & 714 & 44 & 0.26 \\
\hline 카메라 보관함 & 926 & 893 & 100 & 0.27 \\
\hline 연락처 등록 & 753 & 714 & 64 & 0.13 \\
\hline 새메세지 & 924 & 915 & 121 & 0.45 \\
\hline Mplayon & 763 & 859 & 77 & 0.38 \\
\hline
\end{tabular}


또한 동적인 모델 역시 정적 모델과 동일하게 물리적인 시간(0 138ms)이 전체 수행시간에 별다른 영향을 미치지 않았는데(Figure 5) 이는 기존 연구(Kong et al., 2008)의 분석 결과와 마찬가지로 물리적인 과정보다 인지적인 과정 이 더 중요하게 미치는 것을 확인할 수 있었다.

동적 메뉴 모델의 경우 정적 메뉴 모델보다 더 높은 상관 관계와 결정 계수가 산출되었는데 이는 터치스크린의 특성 을 고려한 메뉴였기 때문인 것으로 분석된다. 즉 동적 메뉴 모델은 사용자가 선택한 위치에서부터 빈도수 순으로 메뉴 item이 배치되기 때문에 다른 메뉴 item을 찾아볼 필요가 없다. 앞서 언급한 바와 같이 물리적인 과정보다 시각적 탐 색을 포함한 인지적인 과정이 수행도에 더 영향을 미치기 때문에 이와 같은 시각적 탐색 과정이 생략됨으로써 실제 실험 값에 더 가까운 것으로 분석된다.

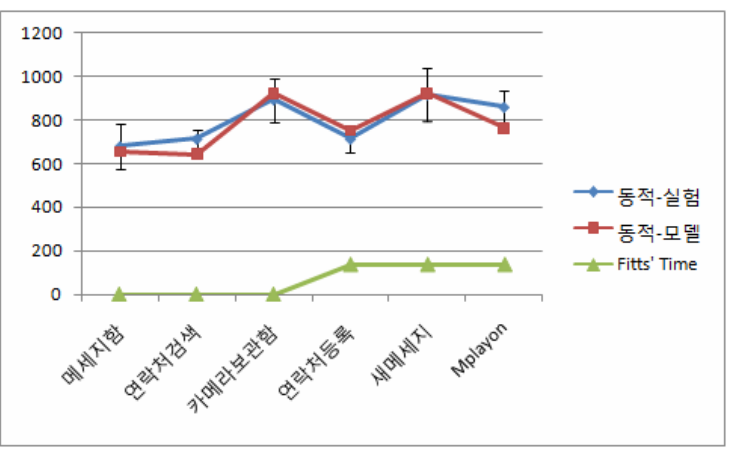

Figure 5. 동적 모델의 결과 그래프

정적 메뉴 모델과 동적 메뉴 모델 모두 실제 실험 값에 비해 그 수행시간이 적게 예측되는 경향을 보였는데, 이것은 정적이나 동적 메뉴 모델의 특성 때문인 것으로 보여진다 (Figure 4,5). 즉, 정적 모델의 경우 ACT-R 모델은 타겟 의 위치에 따라 그 예측 값이 결정되는 반면, 실제 피 실험 자는 경우에 따라 원하는 타겟과 현재 바라보는 타겟과의 매칭(Matching) 시간 등에서 차이가 나는 것으로 판단된다. 또한 동적 모델은 메인 화면에서 다음 화면으로 넘어갈 때 현재 손의 위치에 가까이 메뉴가 편성되어 있는데 모델은 그 위치를 바로 인식하는 반면 피 실험자는 잠시 한번이라 도 다른 곳을 보면 그 만큼의 시간이 소요되기 때문인 것으 로 분석된다.

\subsection{Kong(Kong et al., 2009) 연구와의 결과 비교}

본 연구에서는 기존의 연구인 Kong (Kong et al., 2009) 연구 결과와 마찬가지로 정적 메뉴 모델보다 동적인 메뉴 모델에서 그 수행도가 더 좋음을 모델 예측 값을 통해 확인
하였다 $(p$-value <0.00). 또한 메뉴 구조에 따라 전체 수행 중 물리적인 과정과 인지적인 과정을 분리하여 분석한 결과 Kong (Kong et al., 2009)의 연구 결과와 마찬가지로 인지 적인 과정이 더욱 중요하게 영향을 미침을 확인하였다.

\section{4. 검 토}

본 연구는 기존까지의 연구 방법인 피 실험자들 기반으로 하는 평가와는 달리 인지모델을 이용한 수행도 예측해 보 았다. 기존의 연구 결과로 발표된 실험(Kong et al., 2008) 이었던 터치스크린 환경의 Task를 $\mathrm{ACT}-\mathrm{R}$ 이라는 인지 아 키텍쳐를 이용해 모델링하여 그 데이터 값과 비교한 결과, 피 실험자들의 행위 패턴을 그대로 따르고 있음은 물론 정 확한 예측 값을 확인할 수 있었다. 기존의 연구(Kong et al., 2008)는 손을 이용한 터치스크린 환경에서 이루어진 실험 이었기 때문에 본 연구에서도 그에 동일한 조건을 맞추기 위하여 ACT-R 모델의 Motor module에 기본 값으로 지 정되어 있는 Fitts' Law의 coefficient 값을 손의 움직임에 맞게 수정하였다(Kong(Kong et al., 2009)연구의 실험 툴 인 MFD Tool의 coefficient 값을 그대로 사용함).

본 연구 결과에서 볼 수 있듯이 모델링의 예측 값 역시 기존 연구의 결과와 동일하게 정적인 인터페이스보다는 동 적인 인터페이스에서 그 수행시간이 짧게 나타남을 확인할 수 있었다. 또한 전체 수행 결과를 물리적인 과정과 인지적 인 과정으로 분리하여 비교한 결과 물리적인 과정보다 인지 적인 과정이 전체 수행도에 미치는 영향이 더욱 중요하게 나타남을 확인할 수 있었다.

본 연구는 기존의 메뉴 선택 과정에서 일어나는 시각적 탐색 과정인 exhaustive search(Nilsen, 1991)가 아니라 pre-attentive search를 이용하였다. 인간의 중심와(Fovea) 의 각도인 $2^{\circ}$ 와 모니터와 눈과의 거리를 계산하여 한번에 볼 수 있는 메뉴의 수(2개)를 정하고 모델을 수립하였는데 이는 실제 피 실험자의 data에서도 확인할 수 있었다. 과제 인 '카메라 보관함'과 'Mplayon'은 각각 상위에서 3번째, 4 번째 위치해 있음에도 불구하고 그 수행시간의 차이가 전혀 나타나지 않았다.

그 결과 메뉴 선택 과제에 대해 exhaustive search를 할 때 보다 pre-attentive를 이용한 수행 예측이 실제 data와 더 유사한 결과를 보였다. 따라서 메뉴 선택 과제 등의 간 단하고 익숙한 과제일 경우, 그 시각적 탐색 과정이 메뉴 하나하나에 attention을 주기보다는 인간의 시각적 특성을 고려한 pre-attentive 전략이 실제와 가깝다는 것을 알 수 있었다. 
하지만 정적 메뉴 모델과 동적 메뉴 모델 모두에서 시행 한 6가지 과제 중 2 3가지 과제가 비교적 실제 수행도보 다 낮게 예측하는 경향을 보였는데 이것은 두 가지 이유로 분석된다.

첫 번째는 시행하는 task가 메인 화면에서 타겟 메뉴 화 면으로 넘어간 뒤 타겟을 찾고 누르는 시간만을 확인하는데 이는 대략 $1,000 \mathrm{~ms}$ 남짓하는 시간이다. 때문에 피 실험자 들의 순간 시선처리에 따라 그 편차가 크게 나타났기 때문 이고 그로 인한 수행시간의 차이가 발생한 것으로 판단된다.

두 번째로는 ACT-R 모델의 시선을 옮기는 시간이 185 ms으로 고정되어 있는데(Anderson, 1997) 이는 움직이는 거리에 관계없이 기본 값으로 사용되고 있다. 그렇기 때문에 메뉴를 선택하는 Task 환경인 경우 비교적 작은 인터페이 스에서 수행이 이루어 지므로 시선을 옮기는 시간이 다른 경우보다 적게 걸리게 된다. 따라서 이로 인한 실제 수행시 간과 모델 예측 값과의 오차가 생긴 것으로 판단된다. 현재 $\mathrm{ACT}-\mathrm{R}$ 의 모델을 이용한 연구 분야를 보면 간단히 한 가 지 번호를 선택하는 $\operatorname{task}(N i l s e n, 1991)$ 에서부터 자동차 driving simulation(Salvucci, 2005, Salvucci \& Taatgen, 2007, Brumby \& Salvucci, 2006)까지 다양한 분야에서 인지 아키텍쳐인 ACT-R이 사용되고 있다. 따라서 연구의 특성이나 Task가 이루어지는 환경에 따라 시선이나 주의 (Attention) 가 옮겨지는 시간을 조절하는 것이 정확한 모델 을 수립하는데 도움이 될 것으로 생각된다.

본 연구는 비교적 단순한 메뉴 선택에 대한 수행 예측이 었지만 그 결과는 기존까지의 사용성 평가에 대한 방법론의 단점을 보완하는 방법론으로 사용될 수 있음을 시사한다. 서 두에서 언급한 바와 마찬가지로 인지 모델을 이용한 사용성 평가는 실제 피 실험자를 대상으로 하는 평가에 비해 큰 장 점을 제공한다. 즉, 평가를 위한 비용과 시간을 절약할 수 있 으며 피 실험자 간의 개인차를 고려하지 않아도 된다는 것 이다. 인지 모델을 이용한 수행도 예측의 범위를 확대하여 연구한다면 실제 사람이 실험하기 어려운 환경이나 위험한 환경에서의 평가도 충분히 가능할 것이다. 특히 $\mathrm{ACT}-\mathrm{R}$ 모 델의 경우 GOMS 등과는 달리 상대적인 인터페이스의 비 교는 물론 절대적인 수행시간까지 예측이 가능하며 그 범위 도 다양하게 적용될 수 있다(Anderson et al., 2004). 게다 가, 모델링의 개념이나 기술 등이 $\mathrm{HCI}$ 의 개발자나 인터페이 스 개발자에게 매우 유용하게 사용되고 있으며 최근 사용자 인터페이스의 개선이나 설계에 이용되는 추세를 감안한다면 $\mathrm{ACT}-\mathrm{R}$ 을 비롯한 인지 모델링에 많은 연구가 진행되어야 함이 분명하다.

따라서 본 연구 결과는 모델을 이용한 수행도 예측에 대 한 연구가 시발점에 놓인 현 상황에서 $\mathrm{HCI}$ 를 포함한 사용 성 평가에 있어 많은 도움이 될 것이라 기대된다.

\section{5. 결 론}

본 연구를 통해 다음과 같은 결론을 얻을 수 있었다.

첫 번째는, 인지 아키텍쳐인 ACT-R모델을 통해 터치스 크린 환경에서의 메뉴 선택 수행도를 예측할 수 있었고, 두 번째는 그 예측 값이 실제 실험 값과 비교한 결과 정확한 수행도를 예측한다는 것을 알 수 있었다.

\section{참고 문헌}

http://act-r.psy.cmu.edu

Amant, R., Horton, T. E. \& Ritter, F. E., Model-based Evaluation of Expert Cell Phone Menu Interaction. Transaction on Computer-Human Interaction. 14, 1, Article 1, 2007.

Anderson, J. R., The Architecture of Cognition. Cambridge, MA: Harvard University Press, 1983.

Anderson, J. R., ACT: A simple theory of complex cognition. American Psychologist, 51, 355-365, 1996.

Anderson, J. R. \& Bower, G. H., Human associative memory. Winston, D.C: V. H. Winston, 1973.

Anderson, J. R., Matessa, M. \& Lebiere, C., ACT-R: a theory of higher level cognition and its relation to visual attention. Human Computer Interaction, 12, 439-462, 1997.

Anderson, J. R., Bothell, D., Byrne, M. D., Douglass, S., Lebiere, C. \& Qin, Y., An integrated theory of mind, Psychological Review, 111, pp. 1036-1060, 2004.

Brumby, D. P. \& Saluvicci, D. D., Towards a constraint analysis of human multitasking. In Proceedings of the Seventh International Conference on Cognitive Modeling (pp. 353-354). Trieste, Italy, 2006.

Byrne, M. D., ACT-R/PM and menu selection: applying a cognitive architecture to HCI, International Journal of Human-Computer Studies, Volume 55, Issue 1, July 2001, Pages 41-84, 2001.

Byrne, M. D. \& Anderson, J. R., Enhancing ACT-R's perceptual-motor abilities. In Proceedings of the Nineteenth Annual Conference of the Cognitive Science Society. Hillsdale, NJ: Lawrence Erlbaum Associates, 1997.

Card, S., Moran, T. \& Newell, A., The psychology of human computer interaction. Hillsdale, NJ: Erlbaum, 1983.

Cockburn, A., Gutwin, C. \& Greenberg, S., A predictive model of menu performance. In Proceedings of the ACM Conference on Human Factors in Computing Systems (CH1'07), 627-636, 2007.

John, B. E. \& Kieras, D. E., The GOMS family of user interface analysis techniques: Comparison and contrast. ACM Transactions on Computer Human Interaction, 3, 320-351, 1996.

Kieras, D. E. \& Meyer, D. E., An overview of the EPIC architecture for cognition and performance with application to human-computer interaction. Human-Computer Interaction 12, pp. 391-438, 1997. 
Kong, B. D., Min, J. S. \& Myung, R., Menu design for touch screen interfaces, Human Factors and Ergonomics Society 53th Annual Meeting Proceedings, Volume 53, Number 15, pp. 950-954(5), 2009.

Laird, J. E., A. Newell \& Rosenbloom, P. S., SOAR: An architecture for general intelligence, Artificial Intelligence 33, pp. 1-64, 1987.

Nilsen, E. L., Perceptual-motor control in human-computer interaction (Tech. Rep. No. 37). Ann Arbor, University of Michigan, Cognitive Science and Machine Intelligence Laboratory, 1991.

Olson, J. R. \& Olson, G. M., The Growth of Cognitive Modeling in Human-Computer Interaction since GOMS, Human-Computer Interaction, 5, 221-265, 1990.

Ritter, F. E. \& Young, R. M., Introduction to this special issue on using cognitive models to improve interface design, Int. J. HumanComputer Studies, vol. 55, pp. 1, 2001.

Salvucci, D. D., A multi tasking general executive for compound continuous tasks. Cognitive Science, 29, 457-492, 2005.

Salvucci, D. D., Modeling driver behavior in a cognitive architecture. Human Factors, 48, 362-380, 2005.

Salvucci, D. D. \& Taatgen, N. A., An integrated approach to modeling concurrent multitasking. In The 29th Annual Conference of the Cognitive Science Society. Nashville, Tennessee, 2007.

Taatgen, N. A. Lebiere, C. and Anderson, J. R., Modeling paradigms in ACT-R, Cognition and Multi-Agent Interaction, Cognitive Modeling to Social Simulation, E. Sun, Ed., Submitted for publication, 2004.

\section{저자 소개}

민 정 상 myu1123@korea.ac.kr 고려대학교 산업공학과 학사 현 재: 고려대학교 산업경영공학과석사 과정 관심분야: 인간공학, User Interface, 인지공학

\section{조 성 식 jossyes@korea.ac.kr}

M.S. in mechanical engineering, Auburn University 현 재: 고려대학교 산업경영공학과박사 과정 관심분야: Cognitive architecture, Ergonomics

\section{명 노 해 rmyung@korea.ac.kr}

Ph.D. in Industrial Engineering, Texas Tech University 현 재: 고려대학교 산업경영공학과 교수

관심분야: Cognitive Engineering, $\mathrm{HCI}$

논 문 접 수 일 (Date Received) : 2010년 10월 28일

논 문 수 정 일 (Date Revised) :2010년 11월 29일 논문 게재승인일 (Date Accepted) : 2010년 11월 30일 